\title{
David Hume e o Hiato entre o Ponto e a Linha: OS PRINCÍPIOS DA DIMENSÃO ESPACIAL
}

DAVID HuME AND THE GAP BETWEEN THE POINT AND THE LINE: THE PRINCIPLES OF SPATIAL DIMENSION

\author{
MARCOS CÉSAR SENEDA \\ Universidade Federal de Uberlândia (UFU) / CNPq, BRASIL \\ mseneda@ufu.br
}

\begin{abstract}
The aim of this paper is to present the copy principle from execution of the principle of separability for the purpose of elucidating the discussions conducted by Hume in understanding the composition of space and its implications for the sciences that operate with spatial constructions. The particular epistemic gain here is to do this within a model of empiricism. Given that there are several irregularities in the manner of analyzing a complex and extracting simple elements from it, as will be demonstrated here, we seek to show that separating a complex considering its simple qualities and decomposing a complex to determine its simple quantities is completely different. Thus, we seek to show how Hume needed to recreate his own cognitive model, strongly based on noting our perceptions, to be able to use it to conceive the composition of space and the operations of geometry that must make reference to it.
\end{abstract}

Keywords: David Hume $\bullet$ Pierre Bayle $\bullet$ space $\bullet$ simple $\bullet$ complex $\bullet$ geometry

\section{A definição do simples}

Um problema crucial da semântica empirista de Hume é a polissemia dos termos simples e unidade. A definição clara do simples é um pressuposto que percorre cada página do Tratado $;^{1}$ e a definição de unidade também é bastante reivindicada, mas torna-se decisiva na Parte II do Livro I do Tratado. Muitos dos problemas que Hume almeja e até mesmo reivindica resolver exigem o emprego da noção operatória que articula o simples e o complexo. A memória e a imaginação se articulam a partir dessas noções; o teste da linguagem, ${ }^{2}$ que Hume sempre emprega no exame das noções metafísicas, delas depende inteiramente; e o jogo das paixões ganha ímpeto a partir do seu entrelaçamento.

O princípio da cópia é uma noção verticalizada, ou seja, que se estabelece entre uma impressão simples e uma ideia simples que lhe deve ser correspondente. Por isso, não deveria admitir erro ou equívoco hermenêutico em Hume, pois diz respeito, 
diretamente, à aquisição de conteúdos. Desse modo, as percepções mais intensas, impressões, devem dar origem às menos intensas, ideias, devendo ambas se espelharem com muita fidelidade. Portanto, tudo o que esteve presente nas impressões deve se reapresentar especularmente na memória e na imaginação (T 1.1.3.1). Mas memória e imaginação operam horizontalmente com esses dados perceptivos, e isso pode perverter ou invalidar o princípio da cópia, ${ }^{3}$ pois nem todo o composto pode ser remetido ao supostamente simples que lhe deu origem.

Hume percebe que há um problema semântico com o composto no tocante à direção da remissão armazenada em suas ideias. As ideias complexas são um desafio constante das análises do Tratado, porque elas podem compor entes mentais imaginários que, tomados como um indivíduo, não encontram um referente no âmbito das nossas percepções. Isso decorre do fato de a composição formar uma unidade fictícia que pode não ter correspondência com a empiria originária que lhe deu origem. $\mathrm{O}$ problema semântico da cópia, em Hume, sempre transita entre a empiria originária e a composição imaginária. Para resolver isso explicitamente, Hume frisa bem no início do Tratado a seguinte propriedade das percepções: "Convém observar ainda uma segunda divisão entre nossas percepções, que se aplica tanto às impressões como às ideias. Trata-se da divisão em simples e complexas" (T 1.1.1.2). E Hume prossegue, definindo esse recurso epistemológico de maneira bem direta: "Percepções simples, sejam elas impressões ou ideias, são aquelas que não admitem nenhuma distinção ou separação. As complexas são o contrário dessas, e podem ser distinguidas em partes" ( T 1.1.1.2). Com uma definição tão direta, parece que tudo se esclarece. E Hume segue a reflexão com um exemplo aparentemente bem descomplicado: "Embora uma cor, sabor e aroma particulares sejam todos qualidades unidas nesta maçã, é fácil perceber que elas não são a mesma coisa, sendo ao menos distinguíveis umas das outras" (T 1.1.1.2). Se elas são distinguíveis, são separáveis. Esse é o segundo princípio epistemológico de maior abrangência do Tratado, que, junto com o princípio da cópia, posiciona-se no front das batalhas contra as velhas categorias metafísicas. O princípio da cópia assegura a correspondência entre ideia e impressão. O princípio da separabilidade opera por degraus: ele auxilia a checar se o todo da ideia pode ser dado na impressão; ou quais partes da ideia podem ser encontradas nesse domínio; ou ainda se nenhumas das partes da ideia podem ser remetidas à impressão, sendo essa ideia, portanto, considerada vazia. Apresentados dessa maneira, esses dois princípios articulam-se de modo elegante. Todavia, o intercâmbio entre os dois princípios, à primeira vista direto e eficaz, é na verdade acidentado e requer várias mediações, apresentando as mesmas dificuldades nos dois extremos, conforme se caminhe para o macro ou para o micro, ${ }^{4}$ ou seja, na direção do complexo ou do supostamente simples.

E o macro não se define por uma ampliação moderada de escala, mas pode ser concebido em medida bem desproporcional. Podemos ver isso no exemplo tomado 
das duas cidades, as de Paris e de Nova Jerusalém:

Observo que muitas de nossas ideias complexas nunca tiveram impressões que lhes correspondessem, e que muitas de nossas impressões complexas nunca são copiadas de maneira exata como ideias. Posso imaginar uma cidade como a Nova Jerusalém, pavimentada de ouro e com seus muros cobertos de rubis, mesmo que nunca tenha visto nenhuma cidade assim. Eu vi Paris; mas afirmarei por isso que sou capaz de formar daquela cidade uma ideia que represente perfeitamente todas as suas ruas e casas, em suas proporções reais e corretas? (T 1.1.1.4).

Os problemas aqui encontrados são gerados pela própria escala dos exemplos. No primeiro caso, o da Nova Jerusalém, ele se enquadra bem no jogo dos dois princípios, uma vez que, conquanto o seu todo, enquanto ideia complexa, jamais integre qualquer experiência no domínio das impressões dos sentidos, o princípio de separabilidade me dá as ferramentas para que cada uma de suas partes possa ser encontrada de modo claro e direto nesse referente. Assim, a imaginação pode conceber uma cidade descendo inteira do céu, e pode igualmente agregar-lhe portas, muralhas e pilastras de pedras preciosas. ${ }^{5}$ Aplicado o princípio da separabilidade, e decomposta a ideia complexa em suas ideias simples, o princípio da cópia volta a exercer toda a sua eficácia. Já o segundo caso, da cidade de Paris, enquanto objeto e tarefa epistemológica é bem mais complexo. Mesmo que eu procure conceber as ruas pelas quais transitei de modo habitual, muitos dos detalhes assegurados pelo princípio da cópia me escaparão. E o princípio da separabilidade não melhora a acribia do concebido, porque o problema aqui é de escala. Seria uma tarefa ingente, infinita e destituída de significado fazer a partição das percepções que compõem uma cidade. De um lado, há o problema da pletora de percepções; de outro lado, há a dificuldade relacionada ao grau de atenção com que cada uma dessas percepções foi colhida. Desse segundo ponto de vista, inclusive, é impróprio tentar decompor o complexo, se o mais simples se encontra destituído de nitidez. Por isso, se ampliarmos muito a escala, começaremos a encontrar casos em que o mais norteador dos princípios, o da cópia, começa a ficar borrado.

Um outro uso desses dois princípios volta-se para o âmago da filosofia. Nesse, o princípio da separabilidade é um recurso anti-metafísico que assegura o acesso ao simples; e o princípio da cópia é o recurso semântico para assegurar que esse simples tem algum significado. Essas duas ferramentas sempre entram em cena quando Hume se incumbe de algum serviço anti-metafísico, por exemplo, o esquartejamento do conceito de unidade substancial. ${ }^{6}$ Numa passagem do Tratado assim talhada, denominada "Da filosofia antiga", Hume assim comenta um dos engodos da imaginação:

Assim, a cor, o sabor, a forma, a solidez e outras qualidades, combinadas em um pêssego ou melão, são concebidas como formando uma coisa; e isso 
em virtude de sua estreita relação, que as faz afetar o pensamento como se não possuísse nenhuma composição. Mas a mente não pára aqui. Sempre que observa o objeto de outra perspectiva, constata que essas qualidades são todas diferentes, distinguíveis e separáveis entre si. E essa perspectiva [...] obriga a imaginação a fantasiar um algo desconhecido [... ], como princípio de união ou coesão entre essas qualidades, capaz de dar ao objeto composto o direito de ser chamado de uma coisa [... ]. (T 1.4.3.5).

Essa passagem retoma com termos e argumentos bastante similares, a Seção VI, "Dos modos e substâncias", do início do Tratado, em que Hume afirma: "[... ] a diferença entre essas duas ideias consiste no fato de que as qualidades particulares que formam uma substância são comumente referidas a um algo desconhecido, a que supostamente elas são inerentes" ( $\mathrm{T}$ 1.1.6.2). Nossa primeira observação é sobre qual a definição de simples que aí se encontra. Nesta passagem, Hume faz uma análise da percepção do ouro, ${ }^{7}$ na anterior, da percepção de um pêssego ou melão. Ambas as análises, assim como a da maçã, supracitada, embora alocadas em contextos diferentes, são empreendidas mediante o princípio da separabilidade, que afirma que tudo o que é diferente é separável. Qual a função desse princípio? Em primeiro lugar, nos conduzir às percepções simples; em segundo lugar, impedir que o complexo abrigue elementos ou estruturas metafísicas ou ontológicas que não podem ser detectadas em sua composição. ${ }^{8} \mathrm{Na}$ análise do exemplo da maçã, o princípio da separabilidade cumpre a primeira função aqui indicada; na análise dos casos do ouro, e do pêssego ou melão, cumpre as duas. Caminhamos, portanto, do complexo para o simples. Mas o que estamos separando? Única e exclusivamente qualidades. É claro que nos casos do ouro e do pêssego ou do melão, Hume está interessado em fazer uma análise da relação de identidade. Hume indica que mesmo quando se trata de qualidades determinadas jungidas na sincronia, o exame atento da mente ali nada mais encontra do que uma coleção de ideias particulares, as quais a mente submeteu a um princípio de união que seria o fundamento da ideia complexa. A esse princípio de união a mente denomina substância, a qual tem a função de compor o vínculo estreito de coesão entre as qualidades particulares. É esse princípio de união, fraudado pela imaginação, que nos possibilita conceber essa coleção de qualidades particulares "[... ] como formando uma coisa [...]" (T 1.4.3.5).

Isso significa, para Hume, que todos os equívocos "nominais", presentes nos jogos e raciocínios metafísicos, poderão ser resolvidos pelo recurso "último" a uma unidade perceptual mínima. Isso não significa que alcançamos uma solução para o problema da verdade (pois o juízo sobre o mundo externo continua em suspenso), mas que conseguimos uma solução para o problema da equivocidade e, principalmente, para a questão da não significatividade. Ou seja, Hume não recusa o significado dos termos metafísicos (pois, para tanto, teria de alcançar um ponto de vista arrimado em outra via metafísica), mas assinala, frontalmente, sua incapacidade de referência percep- 
tual no âmbito de uma semântica empirista. Despir um termo de sua capacidade de referência perceptual e explicitar sua não significatividade é um recurso básico das demolidoras análises metafísicas de David Hume.

A díade simples-complexo decorre do princípio de separabilidade, e nos auxilia, portanto, a decompor e a anular o princípio de identidade substancial. Se o princípio da identidade substancial chega a ser anulado, é porque não resiste ao teste do simples, ou seja, ao decompor o complexo, não se alcança o simples a que esse princípio deveria se remeter, e infere-se que, caso ele possua algum significado, este encontrase destituído de referência empírica. Mas insistamos mais uma vez. O que significa o simples nesse caso? Trata-se nada mais do que a decomposição e o isolamento das qualidades particulares. Isto é, quem utiliza a díade simples-complexo, e caminha na direção do simples, defronta-se com uma qualidade, jamais com uma quantidade.

Assim, quando isolamos o simples, decompositivamente, descobrimos que sua dimensão qualitativa não é congruente com sua dimensão quantitativa. Ou seja, quando separamos as qualidades de um objeto, até atingir as partes que não mais exibem quaisquer distinções, ainda assim podem remanescer quantidades de notável grandeza, às quais jamais nos referiríamos como simples. É esse tipo de incongruência que tensiona a supostamente fácil utilização da distinção simples/complexo. Se tomarmos os exemplos anteriormente citados, veremos que eles recobrem as seguintes qualidades: cor, sabor, aroma, forma, solidez, peso, maleabilidade, fusibilidade, solubilidade. Sabor e aroma são qualidades destituídas de dimensão espacial. As outras qualidades podem ser espacializadas, na medida em que forem estimadas pela visão ou pelo tato. Ou seja, escapa ao olhar arguto dos comentadores que ao se utilizar esses três princípios básicos do empirismo (princípio da cópia, princípio da separabilidade, distinção simples-complexo), nada se disse sobre quantidade. ${ }^{9}$ Os três se aplicam a correspondências ou distinções entre qualidades. A grande dificuldade está em que na Parte II do Livro I do Tratado, Hume precisa lançar mão da noção de ponto, que desempenha uma função quantitativa, pois por ela principia a concepção do espaço, mas não pode abrir mão dos três princípios acima elencados, que ele operacionaliza, como visto acima, em sua função qualitativa.

Nós devemos então caminhar diretamente para a pergunta em geral evitada nos comentários críticos sobre esse problema: a ideia do ponto corresponde a uma dada impressão? Ou seja, a ideia do ponto pode atender ao princípio da cópia, ${ }^{10}$ conforme é usado maiormente no Tratado como estrutura semântica basilar do empirismo? A dificuldade para se responder a isso é muito grande, devido à complexidade que essa questão envolve. A rigor, o ponto não atende ao princípio da cópia, nem às duas arquitraves que lhe dão sustentação, ou seja, ao princípio da separabilidade e à díade simples-complexo. Ele é avesso a essa tríade epistemológica, que forma a estrutura basilar do empirismo circunscrito por Hume. Desvinculando-nos agora dos exemplos, que nos deram arrimo até aqui, entendamos isso a partir da sinopse trabalhada a 
seguir de modo mais conceitual.

No Tratado não há uma única passagem - ousamos dizer isso - em que Hume se valha do vigor semântico do princípio da cópia para validar o ponto. Em primeiro lugar, trata-se de estrutura generalíssima, que pode corresponder a qualquer coisa dotada de pigmentação e visibilidade. $O$ ponto pictórico $^{11}$ não pode atender ao princípio da causalidade, mas pode atender às relações de semelhança e contiguidade, que estão aderidas a todas as propriedades da extensão. Em segundo lugar, o ponto, no interior da geometria, tem semântica própria, e adquire propriedades no seio do complexo à medida que congrega outras dimensões; no entanto, esse complexo não pode ser explicado por seu elemento simples tomado isoladamente. Ou seja, o complexo formado por pontos, a partir de sua disposição, excede as propriedades do seu elemento constituinte atomizado. Esse é um hiato pouco apreciado pela crítica especializada, mas que salienta uma descontinuidade importante: no trajeto analítico, não há como se passar da linha ao ponto. ${ }^{12}$ Por isso, o ponto é um núcleo de imponderabilidades.

Também não podemos ter acesso ao ponto pelo princípio da separabilidade, pois, se tomarmos o Tratado como um livro de exercícios, como muitas vezes o é, veremos que as partes decompostas nos seus exercícios continuam sendo aspectos qualitativos de algo, e esse algo guarda sempre alguma semelhança com o seu referente, sem que a decomposição do complexo jamais caminhe na direção da parte atômica - seja ela qual for - constituinte do objeto em questão. Então o princípio da separabilidade é uma arma contra os engodos de ligeiríssimos pés da incansável metafísica, e ele visa sempre a um confronto da ideia com um dado supostamente externo, que possa ser comprovado através do jogo semântico entre uma ideia e seu referente. Mas um ponto pode ser confirmado por qualquer dado pictórico, e se pode ser confirmado por um quase-tudo de possibilidades, então essa confirmação torna-se trivial.

Quanto à díade simples-complexo, que é um corolário do princípio da separabilidade, no caso do ponto temos acesso a um simples cujas propriedades não estão contidas no referente complexo do qual ele faz parte, nem lhe são transferíveis. No caminho da decomposição, quando atingimos o ponto, a extensão desaparece. Mostrase então algo paradoxal! Em todos os exemplos citados anteriormente é sempre fácil passar do todo à parte e da parte ao todo; as peças do quebra-cabeça encaixam-se bem nos dois sentidos, seja da decomposição ou da composição (lembremo-nos das cidades de Nova Jerusalém e Paris, e dos exemplos do ouro, do pêssego ou melão, e da maçã). No caso da linha e do ponto não há passagem, mas aporia, porque nós temos que passar do extenso para o inextenso e vice-versa. Se concebemos a linha como uma conjunção de pontos, essa ideia parece se apresentar naturalmente à nossa mente. Mas se afirmamos que a extensão se compõe de pontos inextensos, então o que parecia natural agora requer um esforço íngreme da nossa compreensão, e a contradição salta à vista. Remanesce, portanto, um hiato entre o simples e o complexo, 
ou entre o ponto e a linha. Ao recuarmos, encontramos algo inextenso, e que é a base de propriedades que ali não se encontram.

\section{A unidade perceptual}

Nesse problema da crítica à unidade substancial, retratado nos exemplos anteriormente examinados, se estamos decompondo o complexo para alcançar o simples, ainda assim nossa análise se encontra restrita à possibilidade de atingir o simples no âmbito das qualidades. Concederíamos facilmente, por exemplo, que a cor ou a forma de uma maçã jamais poderiam indicar algo simples do ponto de vista quantitativo. Isso nos mostra o quanto o princípio da separabilidade e a díade simples-complexo são intrincados, plurívocos e demandam um atento exame crítico para podermos saber em que direção estamos procedendo para poder atingir o simples. Isso também põe em relevo uma das chaves de interpretação desse texto bastante utilizada pelos comentadores. Pois, ainda que se possa utilizar heuristicamente o princípio de distinção de razão ${ }^{13}$ ( $\mathrm{T}$ 1.1.7.17-18), ainda assim é preciso, para aplicá-lo com eficácia, definir antes o que seria, do ponto de vista quantitativo, uma unidade perceptual e uma unidade matemática.

O tema da unidade perceptual quantitativa é tão difícil e escorregadiço em seus contornos, que ele se esquiva do princípio de separabilidade. Hume jamais atinge o simples, nesse caso, por separação ou decomposição. Para tanto, vale-se do célebre exemplo da mancha de tinta:

Fazei uma pequena mancha de tinta sobre uma folha de papel, fixai nela os olhos e afastai-vos gradativamente, até uma distância em que finalmente não mais a enxergueis. É claro que, no momento que precedeu seu desaparecimento, a imagem ou impressão era perfeitamente indivisível (T 1.2.1.4).

Notemos que o dispositivo utilizado para obter o simples mudou radicalmente do ponto de vista metodológico: não se trata mais da ferramenta da separabilidade, mas do dispositivo de detecção da indivisibilidade. Hume não quer mais dividi-la arbitrariamente, mas almeja assinalar o seu último registro visual perceptivo. Procedimentalmente, o observador não divide a mancha de tinta, mas dela se afasta, no intuito de isolar o simples no campo da percepção. Qual o crivo para o êxito? Seria alcançar algo indivisível, mas ainda assim detectável no campo da percepção. Ou seja, a menor imagem é quase uma não imagem que guarda ainda a marca de uma percepção.

Na mesma passagem em que comenta o exemplo da mancha de tinta, antecedendo-a, Hume vale-se do exemplo do grão de areia, que ocupa bem menos espaço no comentário especializado: ${ }^{14}$ 
Quando alguém me fala da milésima e da décima milésima parte de um grão de areia, faço uma ideia distinta desses números e de suas diferentes proporções; mas as imagens que formo em minha mente para representar essas próprias coisas em questão não diferem em nada uma da outra, e tampouco são inferiores à imagem pela qual represento o próprio grão de areia, que supostamente excede a ambas em tamanha proporção. Tudo o que é composto de partes é distinguível nessas partes, e tudo que é distinguível é separável. Mas o que quer que possamos imaginar da coisa mesma, a ideia de um grão de areia não é distinguível, nem separável em vinte, e menos ainda em mil, dez mil, ou em um número infinito de ideias diferentes (T 1.2.1.3).

Essa curiosa passagem do grão de areia ordena-se em torno do princípio de separabilidade, enunciado claramente em seu corpo: "Tudo o que é composto de partes é distinguível nessas partes, e tudo que é distinguível é separável” (T 1.2.1.3). No entanto, a observação inicial desloca o contexto habitual do seu emprego, que está sempre referido a limites de decomposição de dados empíricos. Hume afirma que, ao se dividir algo que seja minúsculo para a nossa percepção, é possível ter uma ideia distinta de seus números e diferentes proporções. No entanto, à medida que a divisão progride, a imagem em minha mente do suposto referente empírico permanece inalterada, entrando em descompasso com a divisão matemática. Aqui, a interpretação que se queira conceder ao texto dependerá de como será lida a asserção inicial: i) de um lado, ao lê-la, podemos salientar que é possível formar ideias claras da progressão das divisões matemáticas, mas que há um limite mínimo para a divisão dos nossos dados de percepção; ii) de outro lado, lendo-a, podemos ressaltar que não há sentido em se progredir a divisão para além desse mínimo perceptual, porque, sem possibilidade de remissão ao dado perceptual, o índice da divisão matemática ficaria sem sentido ou significação. Adotaremos aqui a primeira interpretação. ${ }^{15}$ Assumimos, portanto, que Hume não recusa o fato cognitivo de que possamos conceber e distinguir as relações de ideias (relations of ideas) envolvidas nessa divisão. Contudo, recusa que o conteúdo dessas divisões possa ser distinguido do ponto de vista das questões de fato (matters of fact). ${ }^{16} \mathrm{O}$ que Hume indica, no início dessa passagem, é um problema semântico que está na base do seu empirismo, a saber, que a divisão de objetos físicos e matemáticos não pode ser entendida da mesma maneira pela mente.

O grão de areia é apresentado com o princípio da separabilidade, mas, na sequência, Hume vale-se do exercício da mancha de tinta. A dificuldade ingente aqui e pouco salientada é que o grão de areia bem se assimila a um ponto físico, ${ }^{17}$ e por isso guarda ainda o mínimo de sua complexidade. É difícil não concordar com o primeiro degrau da afirmação de Hume, a saber, de que um grão de areia não pode ser dividido pela imaginação em vinte partes; e é impossível não concordar com os outros degraus progressivos da subdivisão. Mas esse recurso ao mesmo tempo matemático e retórico não funcionaria tão bem, caso afirmássemos que poderíamos conceber que um 
grão de areia poderia ser dividido em duas partes. A divisão em dois dessa espécie de ponto físico, o grão de areia, parece não estar fora do nosso alcance. Então, para resolver esse dilema entre o imagético e o não-imagético, é preciso sair do ponto físico, o grão de areia, e passar para o ponto pictórico, a mancha de tinta - e esse é um dos grandes recursos de que Hume lança mão.

No trajeto analítico em que se vale do grão de areia, Hume enuncia explicitamente o princípio da separabilidade, mas não é dele que se serve para determinar um minimum sensorial. ${ }^{18} \mathrm{~A}$ citação desse princípio e sua não utilização nos revelam muita coisa, e nos ajudam a compreender o léxico de Hume. O ponto não é parte, porque tudo o que é separável é composto de partes, e essas partes são necessariamente extensas. Quem atinge o ponto, na linguagem de Hume, atinge o elemento último da não extensão. E essa é uma singularidade do debate que não pode ser elidida na discussão do princípio da cópia. Garrett observa o seguinte: "Seria desconcertante se a ideia de espaço fosse um contraexemplo ao princípio da cópia, pois ele [Hume] salienta a importância do princípio no núcleo de sua exposição da natureza daquela ideia (T 1.2.3.1)" (2008, p.52). Embora comente a questão da disposição espacial das partes, Garrett elide dois problemas, a saber, o de que a extensão já é derivada de uma noção não espacializada, o ponto, e o de que o princípio da cópia assegura somente que nossas ideias simples são cópias de nossas impressões simples. A passagem citada de Garrett indica que essa dificuldade raramente é bem apreciada no debate, ou seja, se o ponto for o elemento simples da ideia de espaço, então ele é incapaz de gerar, na medida em que é simples, a ideia da qual faz parte, porque a ideia de espaço depende de uma disposição dos pontos, a qual jamais poderá ser representada por um ponto tomado isoladamente. Essa é a constatação mais cabal, explícita, do texto de Hume (T 1.2.3), de que a ideia de espaço não preenche o crivo do princípio da cópia, uma vez que quando atingimos o seu componente simples, a saber, o ponto, a unidade de análise se desmanchou.

Esse problema nem sempre é claramente percebido ou, se percebido, deixa de ser intencionalmente explorado, a saber, o do hiato entre o ponto e a extensão. ${ }^{19}$ Aqui nós não poderíamos passar diretamente do simples ao complexo, como o exigiria o princípio da cópia, para simplesmente concluir: "Em qualquer caso, no entanto, essas ideias serão copiadas seja a partir de uma impressão seja de um composto de simples ideias, cada uma das quais tem sido copiada de uma impressão, de acordo com o princípio da cópia" (Garrett 2008, p.52). A singularidade desse ponto da discussão se dá porque o complexo encontra dificuldade para recuar até o simples; e porque no simples, igualmente, não estão anunciadas as propriedades do complexo. Kemp Smith percebeu bem a dificuldade do debate, e põe a inflexão no seu ponto mais crítico:

Ele [Hume] insiste que extensão visual é inseparável de cor. Mas ele não 
aceita o corolário, ${ }^{20}$ que poderia parecer se seguir, de que a cor, tal como apreendida, tem sempre uma extensão, por menor que essa extensão possa ser. Seu ensinamento é que os minima sensibilia, as impressões simples nas quais uma área visual é divisível, são inextensas (1941, p.277).

Kemp Smith percebe o descompasso que ocorre na discussão, quando, na decomposição do espaço, atingimos o seu elemento mínimo, que se mostra então inextenso. Nesse caso, podemos ter uma ideia do simples que é o ponto, mas não podemos ter uma ideia simples da extensão, cujas propriedades só se manifestam no complexo. Esse é um caso singular, mas bem caracterizado, de não aplicação do princípio da cópia.

A dificuldade nesse caso está em que tempo e espaço jamais podem ser conhecidos per se, pois precisam ser instanciados por um outro que é o seu suporte perceptivo. Acerca disso, W. Waxman comenta:

A concepção associacionista e anti-abstracionista da origem das nossas ideias de espaço e tempo restringe de tal modo seu escopo de aplicação que, embora possamos falar o contrário, elas fornecem ao entendimento humano os meios para perceber ou conceber (tornar-se consciente de que) nada [há] de duradouro, exceto complexos não-coexistentes de sensações, emoções e pensamentos existentes instantaneamente, e nada [há] de extenso, exceto no tocante a complexos coexistentes de pontos coloridos ou tangíveis. Em outras palavras, a concepção da origem do espaço e tempo, e as consequências que ele extraiu disso, é tão inteiramente berkeleyana quanto a análise das ideias abstratas o exemplifica [...], e assim traz consigo, de modo similar, uma implicação idealista extrema: coisas imutáveis, e coisas extensas que não são nem visíveis (coloridas) nem tangíveis (moles, secas, lisas, etc.) são, em um sentido ideacional estrito [... ] extremamente ininteligíveis para nós, e somente por meio de certas ficções da imaginação podemos alguma vez, per impossibile, ser induzidos a supor o contrário (2008, p.78-79).

A leitura de Waxman ressalta em Hume um expediente neo-kantiano avant la lettre, a saber, o método do empirismo estabelece para si próprio um limite claro para as conclusões que podem ser geradas no seu domínio, uma vez que delineia por completo uma semântica prévia, que só admite a operação com ideias que tenham sido localizadas no interior das nossas percepções. Mas podemos ir além de Waxman, utilizando seus próprios argumentos. Quando ele descreve a duração como "complexos não-coexistentes de sensações, emoções e pensamentos existentes instantaneamente" e caracteriza a extensão como "complexos coexistentes de pontos coloridos ou tangíveis" (2008, p.78), ele remonta inevitavelmente ao problema de que a parte mínima dessa percepção já é composta por algo complexo. ${ }^{21}$ Há um problema na gênese das ideias de duração e extensão, à qual não pode ser aplicado o princípio da cópia, pois o simples, nesse caso, não contém as propriedades que só começam a se manifestar nos complexos não-coexistentes ou coexistentes. 
O ponto, portanto, é a não-parte, porque é destituído de extensão. Desse modo, o ponto é o elemento perceptivo último, extremo, da decomposição da parte. No momento em que ela se aniquila e em que ainda há um resíduo sensorial, então aí está o ponto. Inversamente, do ponto de vista psicológico, ele é o momento de ansiedade da extensão, ele a aguarda imperceptivelmente. Mais um ponto, que se lhe agregue, e ele entra no reino de suas propriedades. Do ponto de vista psicológico, portanto, parece fácil passar do ponto à linha, é só agregar um ponto a outro ponto. Do ponto de vista epistemológico, a passagem da linha ao ponto mostra toda a sua dificuldade, porque teríamos que regredir do extenso ao inextenso. O teste da mancha de tinta, portanto, faz esse percurso da aniquilação da parte, detendo-se no exato momento em que ainda se colhe o seu último resíduo sensorial. Em seu léxico, Hume está a nos dizer que a ideia de extensão não pode ser destituída desse minimum perceptual para não vir a ser uma não-ideia. Na semântica do empirismo de Hume, toda a ideia destituída de conteúdo empírico ou é pífia ou ao menos de imponderável referencialidade. O ponto, portanto, é a referência última de algo que pode ser assinalado espacialmente.

O que Hume está dizendo, por conseguinte, com o exemplo da mancha de tinta, é que o exercício tem que se deter antes que a ideia mínima que ele contém se transforme em uma não-ideia, que aqui significa destituída de referencial empírico, ou, em linguagem mais direta, destituída de imagem. Hume afirma que o exemplo do grão de areia diz respeito à imaginação; e o caso da mancha de tinta, aos sentidos. Ou seja, vinculando ideia e impressão, Hume indica que há um mínimo perceptual que assegura o princípio da cópia - esse sim um princípio de incontornável função semântica. Por isso a discussão do ponto, da extensão e da infinita divisibilidade em Hume jamais pode ser subtraída da moldura semântica do empirismo, sem perder todo o seu sentido. O grande problema é que para que esse campo semântico gerasse seus significados, ele requereria imagens ou sinais sensoriais que nos indicassem a composição do espaço ou a passagem do tempo. Hume, por conseguinte, não está discutindo a correção das construções matemáticas, mas a questão de se elas podem corresponder a ideias que tenham um conteúdo semântico aferível empiricamente. Por isso, podemos sustentar que, em sua interpretação, a matemática tem um campo semântico formal (relations of ideas) que se defronta com outro campo semântico de conteúdos de fato (matters of fact).

A teoria da extensão e de sua divisibilidade é um desafio ofuscante para a epistemologia de Hume, porque burla os seus principais recursos: ela precisa ser extraída do campo das questões de fato, mas tem ao mesmo tempo de atender às formalizações da matemática. E o mérito de Hume está em não se alistar em nenhum dos lados do debate, abrindo-se ao ingrato desafio de excogitar uma solução própria. Os Nortons, por intermédio de um enciclopedista, nos mostram o que estava em jogo: ${ }^{22}$ 
Chambers, resumindo a disputa de longa data sobre a divisibilidade dos corpos, observa que os epicuristas, em contraste com os peripatéticos e cartesianos, supõem que a alegada divisibilidade infinita da matéria é um absurdo, e negam que todos os corpos são divisíveis (2007, p.710).

Chambers, por sua vez, apontava uma pertinente distinção alegada pelos atomistas, a saber:

Eles acrescentam que há um mundo de diferença entre a divisibilidade de quantidades físicas e matemáticas. Pois toda quantidade matemática, ou dimensão, eles assentem, pode ser aumentada ou diminuída infinitamente, mas quantidades físicas [não são objetos] nem de um [ato] nem de outro (Chambers 1741, p.234, verbete Divisibility).

Essa distinção é importantíssima, porque mantém intacto o domínio da matemática, deixando aberta a possibilidade da divisibilidade infinita. No entanto, valendo-se de uma ontologia atomista, erige uma muralha entre a quantidade física e a matemática. No tocante à semântica, os epicuristas são mais argutos do que os peripatéticos e cartesianos, porque separam o que esses últimos englobam sem impor nenhuma distinção. Os atomistas aceitam a divisibilidade infinita do espaço, mas não a dos corpos. Divisíveis são os corpos, mas até o limite de seu elemento atômico. Para os seus adversários, a propriedade da divisibilidade infinita recobre qualquer extensão, seja física ou matemática. Para Hume, esse tornar-se-á um flanco importantíssimo do debate. Se a extensão for divisível ao infinito, um número igualmente indefinido de suas partes não terá imagem, ficando excluídas do princípio semântico da referência sensorial. Os comentadores insistem muito no limite de nossas percepções, ${ }^{23}$ mas esse é um argumento ontológico que pode descaracterizar a discussão. Metodologicamente, o que está em jogo é a inviabilidade do princípio da cópia como base da semântica do empirismo: na ausência de imagem, não há validade para a ideia respectiva, mesmo que ela possa ser mensurada primorosamente. Isso levado em conta, a tendência de Hume seria deslocar-se para o outro lado do debate, aproximando-se dos atomistas.

Mas Chambers vale-se de um argumento, que também se encontra em Bayle, para tomar de assalto o território dos atomistas. Para tanto, observa o seguinte:

Tudo o que nós podemos dizer sobre esse ponto é que, de um lado, é claro que um corpúsculo extenso tem de ter dois lados, e consequentemente é divisível; pois se não tivesse dois lados, não seria extenso; e se não tivesse extensão, uma junção de tais diferentes corpúsculos não comporia um corpo (1741, p.234).

Pierre Bayle, coetâneo de Ephraim Chambers, também salienta esse paradoxo. ${ }^{24}$ Todo corpúsculo que não é destituído de extensão tem de ocupar o espaço e ser constituído 
de lados, que são suas referências em sua alocação. Ou seja, tudo o que é dotado de extensão tem partes, e essas podem ser divisíveis ao infinito. ${ }^{25}$ Esse tornar-se-á outro flanco estratégico do debate para Hume, porque, se a extensão for composta de pontos físicos, então ela não será composta de indivisíveis, mas será constituída de partes, cuja divisão dará origem a outras partes, podendo esse processo ser perseguido ao infinito.

Hume percebe bem as dificuldades dos dois lados do debate. Se o espaço for composto por átomos ou indivisíveis físicos, ele possuirá lados, e, portanto, será sempre divisível; se ele for composto por pontos matemáticos, dos quais, nas palavras de Euclides, "nada é parte", ${ }^{26}$ então a somatória de pontos inextensos jamais comporá a extensão. Se a solução proposta por Hume é original, é porque ele não pode se posicionar de nenhum dos dois lados da discussão. Portanto, todo o esforço de Hume, nesse caso singular, é pictórico. Não há nenhuma pergunta ontológica sobre o espaço. O esforço de Hume, do ponto de vista do método de síntese, é constituir o espaço como imagem, é determiná-lo de modo pictórico a partir das propriedades da mente humana.

O princípio da cópia está associado a um minimum perceptual, e é esse minimum que assegura sua semântica. Mas há uma distinção muito bem frisada entre a divisibilidade de quantidades físicas e de quantidades matemáticas. Ou seja, quantidades matemáticas podem ser divididas infinitamente sem que as partes subdivididas abdiquem de sua função referencial formal. Já quantidades físicas não podem ser divididas infinitamente sem que seja destruído o minimum perceptual que as referencia. Ou seja, a divisibilidade infinita é um método para se proceder com a noção de limite, portanto, independe de uma função semântica perceptual. Trata-se, portanto, de relações de ideias. No entanto, dividir um quantum perceptual tem implicações semânticas complexas para tudo o que se refere a questões de fato; pois estas não podem ser concebidas por relações de ideias, mas dependem, em última instância, daquilo que tem que poder ser aferido pelos sentidos. Sem a aferição dos sentidos, a fonte de significação da filosofia experimental está aniquilada. Este é um problema eminente para o empirismo, à medida que depende da relação entre uma imagem e sua respectiva sensação. Klaudat observa que "[...] podemos dar à relação entre impressão e ideia, ao 'derivar' [esta última da outra], um outro sentido. Quando equacionamos 'compreender', 'pensar', com 'sentir' é possível conceber que o 'sentir' oferece um critério para a decidibilidade do 'compreender', do 'pensar"' (1997, p.116). Esta equação nos permite decidir se o pensar tem conteúdo ou não mediante o critério aqui elegido de que esse conteúdo tem que ter um referente empírico. Portanto, no centro do empirismo está a decisão acerca de se um pensamento é vazio ou não; ou seja, sobre a separação entre ideias "válidas", ou dotadas de conteúdo, e ideias improcedentes, ou sem referente empírico. Essa grande questão é de difícil solução na Parte II do Livro I sobre a concepção "Das ideias de espaço e tempo". 
Mas o inverso também deve ser investigado: se toda a ideia destituída de conteúdo é inválida, segundo o princípio do empirismo, isso significa que toda a operação formal que ultrapasse os limites da nossa percepção é igualmente destituída de sentido? Frasca-Spada externaliza, em relação a isso, uma posição bastante radical:

A imaginação, no entanto, tende a desconsiderar isso [o processo de divisão e subdivisão], e a perseguir sua propensão de simular um processo sem fim - com uma infinidade de níveis. Esta é uma ficção natural sem qualquer fundamento, seja em nossas práticas ou, no tocante a isso, em relação à capacidade (finita) de compreensão da mente (1998b, p.45).

Se esse argumento anuncia um limite importante da nossa concepção da realidade, extremá-lo também pode ser pouco heurístico, pois nos retira o recurso às relações de ideias como regulativas para se pensar aspectos das questões de fato que têm fundamentos claros em nossa práxis científica. Inferências robustas a partir de dados não perceptuais, que precisam consequentemente ter suas propriedades assinaladas em dados perceptuais, são um recurso recorrente da ciência empírica. Explorar uma semântica perceptual e imagética não significa, portanto, invalidar as operações matemáticas que excedam o limite da nossa percepção. Apenas indica que o ponto de chegada de toda ciência empírica ainda é o dado perceptual da realidade empírica observável.

A questão central aqui é que o princípio da divisibilidade infinita, que tem sua aplicação assegurada para as quantidades matemáticas, não pode ser aplicado em relação ao extenso, se esse deve atender à função semântica do princípio da cópia, pois este tem que poder se referir, por algum meio, a um minimum perceptual. Um grande problema seria o de saber se esse minimum perceptual pode ser identificado com um ponto matemático e assumir a função que lhe é própria - o que Hume assume e defende (por exemplo, T 1.2.2.9) -; outro grande problema seria o de saber se a geometria, assim como a aritmética, poderia ser dispensada da tarefa semântica de ser congruente com a extensão. A solução arguta de Hume é a de equacionar a imperfeição do ponto pictórico com a imperfeição do ponto matemático, gestando entre ambos os elementos condições consistentes de correspondência, sem gerar a expectativa de uma solução idealizada.

\section{O problema da incongruência}

Tudo se passa como se Hume dividisse a matemática do extenso e do não extenso, e afirmasse que a função referencial da geometria depende de que ela toque a realidade em algum ponto perceptual. Para entender o escopo da crítica, nós precisamos separar o lado operacional e formal do lado semântico, com vistas a percebermos melhor o problema metodológico. Do ponto de vista operacional, todas as operações 
estão lógica e formalmente corretas. Elas obedecem logicamente aos princípios de identidade e não contradição. O segundo passo, que jamais aparece no interior da matemática, porque fica a critério da metodologia das ciências empíricas, está na remissão semântica daquilo que foi formalmente construído, de tal modo que o pesquisador possa estar seguro de que para essa construção haja um referente acessível na empiria. O primeiro passo assenta-se em um fundamento lógico; o segundo passo é de cunho metodológico. Os matemáticos jamais consideram isso, porque é um assunto na demarcação da fronteira, de dúplice jurisdição, a saber: de um lado, há o diagrama, construído no interior da própria geometria, e acerca desse há provas consistentes de sua corretude; de outro lado, há o problema, sempre em aberto, da congruência entre a figura e a realidade, ou da aplicação de um objeto matemático a um dado empírico.

O problema da congruência, em relação ao mundo externo, nunca foi cultivado no interior da matemática; pelo contrário, sempre fez parte de capítulos particulares das ciências empíricas. E sempre foi tratado entre os últimos capítulos, ou seja, quando se cobra de uma ciência empírica a prova de sua validade objetiva, ou seja, a comprovação de fato de que o constructo formal teórico consegue tocar determinados componentes do outro lado, externo, da realidade empírica. Esse é um capítulo de metodologia das ciências empíricas. Toda ciência construída com rigor precisa mostrar que seu método é fundamento suficiente da sua semântica, ou seja, tem que assegurar previamente que haja, através de tal método, referência aos objetos elegidos e domínio dos seus componentes no empiricamente dado. Frasca-Spada salienta o radicalismo da filosofia experimental de Hume, cuja semântica exclui a congruência com qualquer coisa que não sejam as nossas percepções. Ela destaca:

Uma vez que é possível supor a existência de uma diferença indeterminável entre nossas percepções e objetos externos, não é seguro, em princípio, transferir para objetos externos aquilo que nós descobrimos sobre nossas percepções. Por outro lado, nós podemos supor que a realidade é diferente da percepção; mas qualquer coisa que imaginarmos acerca disso precisa ser aplicável, em princípio, à percepção. Desse modo, uma restrição é imposta às nossas suposições: ela exclui a possibilidade de objetos externos aos quais não podemos dar sentido, mesmo da maneira a mais geral, em nossos próprios termos - isto é, em termos de percepção (1998b, p.42).

Frasca-Spada explicita bem que a percepção, para nós, é o principal parâmetro de aferição da realidade externa. Trata-se do "tribunal" do filósofo de Edimburgo, prékantiano, erigido contra as pretensões da razão ao emitir juízos sobre o mundo externo. Ele ajuíza uma pergunta sempre perseguida por Hume: qual a posição do objeto externo em relação à nossa percepção? Em Hume a percepção é o único critério semântico consistente para se aceitar a suposição de que há algo posto como externo à mente. É justamente por causa desse critério que a discussão sobre o espaço e o 
tempo se torna dificílima, porque ela tem de ser conduzida, o tempo todo, de maneira indireta, sob o pressuposto de que nossas percepções instanciam todas as possibilidades de acesso que temos ao que é espacial e temporal. O tribunal humiano desabilita a razão na investigação de estruturas a priori da nossa sensibilidade, abrindo a investigação para outra via, perceptual, do surgimento das estruturas geométricas.

Ora, Hume percebe essa dificuldade de acesso a tempo e espaço enquanto estruturas a priori, e dá um passo estratégico atrás, bem epistêmico e matreiro, e se pergunta: onde começa o extenso? Ele precisa se perguntar isso, porque o extenso não surge de sua parte simples, porque ela ainda - como já vimos - não contém suas propriedades. Então o começo do extenso está além do simples. Por outro lado, a linha, enquanto estrutura matemática, por causa da divisibilidade infinita do contínuo, impede que o ponto enquanto estrutura simples se manifeste. A eleição de um ponto pictórico vem então na contramão da história da geometria. Quando Hume põe essa questão, ele dá um passo atrás na discussão das qualidades primárias, forçando quem se interessa por matemáticas ou por epistemologia a discutir metodologicamente as condições de congruência das construções da geometria. O que nós começamos a perceber, através das observações de Hume, é que a geometria se interessa pelo espaço e parece descrevê-lo com exatidão, mas nós não podemos pressupor que temos acesso direto a uma estrutura pura e $a$ priori da espacialidade. A grande questão de Hume é que o espaço físico válido, para nós, é aquele sob o suporte direto das nossas percepções. Só ele está apto a resolver duas questões: a de se há um elemento que pode ser a referência do simples; e a de se ele seria um bom candidato para conter as propriedades do complexo. São as nossas percepções que instanciam as concepções de espaço para nós, não há como separar uma da outra. Uma das insistências de Hume nessa discussão, que caracteriza o seu empirismo obstinado, é a de que as nossas percepções visíveis e tangíveis são a porta de entrada das concepções de espaço a que temos acesso, de tal modo que não há outras concepções válidas para seres que tem a nossa constituição mental.

A grande dificuldade dessa questão é que a matemática não representa as nossas percepções, mas representa a si própria. Daí decorre a dificuldade de se entender tanto a origem da noção de espaço com que ela opera, quanto o modo como ela toca, de volta, a realidade espacial à qual ela supostamente se refere. Nessa questão, Hume soma-se a Bayle, e sai da retaguarda, avançando sobre o terreno do adversário. Não é só ao filósofo que cabe fundamentar a concepção de espaço; cumpre também ao matemático justificar de que modo a noção de espaço com a qual trabalha é fundamento suficiente das figuras que constrói e com as quais opera. Hume e Bayle são grandes teóricos da difícil tarefa de se conceber o que é o espaço. É preciso perceber que o espaço, na matemática, é uma noção não explícita, mas pressuposta (plena de concepções tácitas em seu bojo). ${ }^{27}$ É preciso perceber, por conseguinte, que a dificuldade semântica de saber o que é o espaço se encontra dos dois lados da questão, a 
saber, de quem opera com relações de ideias e de quem quer extrair conhecimentos das questões de fato.

A tese de Bayle é bastante interessante, porque ele não discute as propriedades das construções matemáticas, mas as propriedades da própria extensão. É como se, ao se conceber o espaço perceptualmente e as construções matemáticas idealmente, Bayle afirmasse que as construções matemáticas são tão robustas que o espaço é frágil para suportá-las. Quando exibidas em sua extensão, essas figuras geométricas, segundo Bayle, enganam a visão e a razão, todavia, não em relação às propriedades que comportam, mas no tocante ao espaço que deveria dar sustentação à sua exibição. ${ }^{28} \mathrm{Na}$ concepção anti-kantiana ${ }^{29}$ de Bayle avant la lettre, o espaço não é simplesmente um quantum que dá suporte a um qualis, mas uma qualitas que pode ser objeto de uma quantitas. O fato de poder ser quantizado, não indica, por si só, que ele possa ser objeto exclusivo dos matemáticos. Ou seja, na visão de Bayle o espaço não é puro, mas empírico; destituído de aprioridade, ele é constituído por qualidades de fato secundárias.

Se há, portanto, um hiato entre o ponto e a linha, e se Hume tiver razão, acerca de que o primeiro acesso ao ponto é por uma qualidade secundária, a mancha de tinta, então a congruência é apenas um caso especial de contato entre a geometria e o espaço. Isso nos leva a perguntar se a geometria é um caso particular do uso das nossas percepções, cuja aplicação não pode ser considerada válida irrestritamente. No entanto, dada a incongruência entre as nossas percepções e os supostos objetos do mundo externo, isso nos força ainda a perguntar sobre qual é o componente a que a geometria tem acesso por congruência, em relação aos objetos captados por nossas percepções.

\section{Conclusão}

Diversidade de acepções do simples em Hume indica que não há a exposição de uma teoria unificada da unidade perceptual simples. Pelo contrário, na primeira parte desse trabalho pudemos perceber que a teoria do simples é bastante complexa. Quando Hume, a partir do exemplo da mancha de tinta, insiste no problema de isolar uma unidade perceptual mínima, sua intenção é de explicar a disposição espacial da qual se origina o espaço matematizável. Hume explora um flanco que a geometria deixou aberto, seja ao não definir a noção de ponto, seja ao defini-la insuficientemente. Hume não está procurando determinar esse minimum de um ponto de vista ou em uma escala absoluta. Seu problema é determinar quais são os minima que tornam a ideia de extensão perceptível.

Temos de entender que o grande problema a ser resolvido não é a indivisibilidade do ponto oposta a teoria da divisibilidade contínua infinita, mas é justamente 
o da passagem, inconcebível euclidianamente, do ponto para a linha, e consequentemente do não-espacializado para a disposição espacial. O problema latente, para nos valermos de um exemplo apenas, é que a partir de um grão de areia infinitamente dividido, não poderíamos formar nem linhas nem nenhum tipo de disposição espacial. Ou seja, é sem sentido, para a própria ciência, dividir algo infinitamente, se não se consegue em seu interior produzir nenhuma orientação espacial. Talvez Hume nos auxilie a entender que a matemática, para ser ciência, jamais divide infinitamente objetos empíricos, mas, ao contrário, introduz no interior deles suas próprias construções, que atendem a desígnios que poderão ter uma remissão empírica. Ou melhor, ao prosseguir numa divisão infinita, a matemática divide a si própria, ou seja, a seus próprios elementos ou objetos que estão desconectados de qualquer empiria, e estão, portanto, não aderidos a nenhuma dimensão perceptual espacial.

Transformando o espaço numa qualidade eminentemente secundária, Hume interdita o acesso direto da geometria aos objetos espacializados pela nossa percepção. Mesmo que a informação geométrica seja precisa ou dotada de exatidão, não há nada no extenso, enquanto qualidade secundária, à qual se reduzem nossos objetos sensoriais, que possa lhe corresponder de modo irrestrito. Geometria e objetos determinados por qualidades secundárias seguem a partir de agora caminhos separados, próximos e sempre aproximáveis, dotados de ótimas capacidades de correlação, mas sem poder recorrer então a um fundamento metafísico privilegiado que possa lhes assegurar adequação objetiva ou correspondência direta e imediata.

\section{Referências}

Bayle, Pierre. 1740. Dictionaire historique et critique. [Verbete sobre Zenon d'Elée, $4^{\circ}$ v.]. 5eme Édition. Amsterdam, Leyde, La Haye, Utrecht: P. Brunel. 4 vols. in-folio. [Essa edição é uma cópia daquela de 1730; a paginação é a mesma].

Baxter, Donald L. M. 2008. Hume's Theory of Space and Time in Its Skeptical Context. In: David Fate Norton; Jacqueline Taylor (ed.). Cambridge Companion to Hume, p. 105-46. 2nd Edition. Cambridge: Cambridge University Press.

Beck, Lewis White. 1978. A Prussian Hume and a Scottish Kant. In: Essays on Kant and Hume, p.111-29. New Haven and London: Yale University Press.

Cachel, Andrea. 2017. A ideia de espaço no Tratado da Natureza Humana, de Hume. Philósophos 22(1): 11-36.

Chambers, Ephraim. 1741. Cyclopaedia: or, an Universal Dictionary of Arts and Sciences. London: for James Knapton, John Darby [etc.]. Cyclopædia, or, An universal dictionary of arts and sciences (2 Volumes) - Full view - UWDC - UW-Madison Libraries (wisc.edu) Acesso: 18/01/2021.

Cummins, Phillip. 1990. Bayle, Leibniz, Hume and Reid on Extension, Composites and Simples. History of Philosophy Quarterly 7(3): 299-314.

Euclides. 2009. Os Elementos. Tradução e Introdução de Irineu Bicudo. São Paulo: Editora 
Unesp.

Flage, Daniel E. 1981. Hume's Relative Ideas. Hume Studies 7(1): 55-73.

Frasca-Spada, Marina. 1997. Reality and coloured points in Hume's Treatise. Part 1: Coloured points. British Journal for the History of Philosophy 5(2): 297-319.

Frasca-Spada, Marina. 1998a. Space and the self in Hume's Treatise. Cambridge: Cambridge University Press.

Frasca-Spada, Marina. 1998b. Reality and coloured points in Hume's Treatise. Part 2: Reality. British Journal for the History of Philosophy 6(1): 25-46.

Garrett, Don. 2008. Hume's theory of ideas. In: Elizabeth S. Radcliffe (ed.). A Companion to Hume, p.41-57. Malden: Blackwell Scientific Publishing.

Hume, David. 2001. Tratado da natureza humana: uma tentativa de introduzir o método experimental de raciocínio nos assuntos morais. Tradução de Débora Danowski. 2 ed. rev. e ampliada. São Paulo: Editora da Unesp; Imprensa Oficial do Estado.

Hume, David. 2007. A Treatise of Human Nature: a critical edition. Editado por David Fate Norton, Mary J. Norton. Vol. 1: Texts. Oxford: Clarendon.

Hume, David. 1999. Uma investigação sobre o entendimento humano. Tradução de José Oscar de Almeida Marques. São Paulo: Editora da Unesp.

Hume, David. 2007. An enquiry concerning human understanding. Edição, introdução e notas por Peter Millican. New York: Oxford University Press.

Kant, Immanuel. 1983. Prolegomena zu einer jeden künftigen Metaphysik die als Wissenschaft wird auftreten können. In: Kant, Immanuel. Werke in zehn Bänden. 5. Aufl. Hrsg. von Wilhelm Weischedel. Darmstadt: Wissenschaftliche Buchgesellschaft. Bd. 5.

Kemp Smith, N. 1941. The philosophy of David Hume. A critical study of its origins and central doctrines. London: Macmillan.

Klaudat, André. 1997. A natureza do projeto filosófico em Hume. Manuscrito 20(2): 95-121.

Locke, John. 2014. Ensaio sobre o entendimento humano. Introdução, notas e coordenação da tradução de Eduardo Abranches de Soveral. Lisboa: Fundação Calouste Gulbenkian.

Newman, Rosemary. 1981. Hume on Space and Geometry. Hume Studies 7(1): 1-31.

Norton, David Fate \& Norton, Mary. 2007. David Hume. A Treatise of Human Nature: a critical edition. Vol. 2: Material editorial. Oxford: Clarendon.

Pappas, George S. 1989. Abstract General Ideas in Hume. Hume Studies 15(2): 339-52.

Waxman, Weyne. 2008. Hume and the origin of our ideas of space and time. In: Elizabeth S. Radcliffe (ed.). A Companion to Hume, p.72-88. Malden: Blackwell Scientific Publishing.

\section{Notas}

${ }^{1}$ Tratado aqui será a designação encurtada para Tratado da natureza humana; o mesmo vale para Investigação em relação à Investigação sobre o entendimento humano. O Tratado será citado por T, seguido de Livro, Parte, Seção e Parágrafo. A Investigação será indicada por IEH, seguida por Seção, Parte e Parágrafo. O Ensaio sobre o entendimento humano, de Locke, será designado por EHU, seguindo o mesmo procedimento de citação. As traduções do Tratado são de lavra de Déborah Danowski, e as de Locke, no Ensaio, são de Eduardo Abranches de Soveral, conforme indicado nas referências bibliográficas. Todas as outras traduções são nossas. 
${ }^{2}$ Sua formulação mais direta encontra-se na Investigação (IEH 2.9) e um exemplo de sua utilização pode ser visto no primeiro exame que Hume faz no Tratado no tocante às nossas ideias dos modos e substâncias (T 1.1.6.1). Trata-se sempre de uma aferição semântica dos termos que estamos empregando ao filosofar.

${ }^{3}$ Hume anuncia esse problema no início do Tratado ( $\mathrm{T}$ 1.1.2.1), referindo-se a uma inversão de método, e na sequência passa a tratar do problema das ideias complexas através da análise da memória e da imaginação.

${ }^{4}$ Nesse sentido, a macro percepção de uma cidade pode envolver um grau tão similar de complexidade quanto a relativa micro percepção de uma casa, porque o que está em jogo é a capacidade de separar impressões complexas para identificar as simples de que elas se compõem. Mas esse é um jogo semântico, ele visa a identificar as ideias com as quais se opera, sem jamais supor que o objetivo dessa operação seria levar a cabo qualquer tipo de dissecação minuciosa das nossas percepções. Não é a partição das percepções que interessa ao empirismo, mas a correspondência que pode ser estabelecida entre as que podem ser significativas no jogo da linguagem.

${ }^{5} \mathrm{O}$ exemplo de Hume faz referência ao último livro da Bíblia, o Apocalipse (21, 9-23), em que é configurada e descrita a cidade santa descendo do céu.

${ }^{6}$ Não são poucas as passagens de Locke que podem dar suporte à utilização de Hume do princípio de separabilidade como uma consequência do princípio da cópia, e diversas se concentram no capítulo sobre a crítica do conceito de substância (EHU 1.23). Locke enfatiza, nessa crítica, a combinação habitual de ideias simples pela qual identificamos indivíduos, sem que tenhamos acesso ao seu princípio de unificação: “[... ] qualquer um que reflita sobre os seus pensamentos, descobrirá que não tem ideia de nenhuma outra substância, como sejam o ouro, o cavalo, o ferro, o homem, o vitríolo, o pão, mas apenas possui essas qualidades sensíveis que supõe serem inerentes, com a suposição da existência de um substrato que oferece um suporte para essas características ou ideias simples, as quais observou como existentes em conjunto" (EHU 1.23.6). White Beck observa, de maneira arguta, que "a descrição que Hume dá de objetos percebidos é, na terminologia de Locke, em termos de coexistência e não de causação" (1978, p.124). Ou seja, a análise da coexistência das percepções, em Locke, está à serviço da desconstrução (radicalizada por Hume) do princípio de causalidade.

${ }^{7}$ Essa passagem encontra similitude abrangente no Ensaio sobre o entendimento humano de Locke, em duas passagens em que Locke comenta o ouro como ideia complexa (EHU 1.23.10 e 1.23.37). Na segunda passagem, ao final desse capítulo "Sobre nossas ideias complexas de substâncias", Locke afirma: "[... ] a maior parte das ideias que forma a ideia complexa de ouro é a cor amarela, o grande peso, a maleabilidade, a fusibilidade e solubilidade na aqua regia, etc., todas unidas em conjunto num substrato desconhecido" (EHU 1.23.37 o negrito é nosso). Podemos perceber que o exemplo do ouro, aludido por Hume, é extraído diretamente de Locke. O método de análise é o mesmo, ou seja, se nos valemos do princípio de separabilidade é para mostrar que, após a identificação do simples, não há nenhum resíduo que possa validar o conceito de substância como fundamento de explicação das ideias que aparecem reunidas na sensibilidade. Assim, sempre que a imaginação projeta o conceito de substância no âmago de uma ideia complexa, ela se situa em um terreno que está interditado ao método experimental.

${ }^{8}$ É importante ressaltar que a discussão sobre a definição do simples e do complexo, que é bem explícita no Tratado (T 1.1.1.2), não encontra correspondência na parte que lhe é similar 
na Investigação (IEH 2.5-7), provavelmente porque a discussão de problemas metafísicos representa um papel de bem menor importância nessa obra que Hume escreveu a partir de uma releitura do primeiro livro do Tratado.

${ }^{9}$ Garrett opera com esses princípios, aos quais acrescenta o princípio de conceptibilidade. Frisa, inclusive, - com o que concordamos - que "[...] o próprio princípio de separabilidade é evidentemente uma consequência direta da definição [de Hume] da distinção simples/complexo" (2008, p.53). Ou seja, formam uma díade. No entanto, ao operar com as ideias simples e complexas, Garrett (2008, p.52-4) explora o problema das ideias abstratas ( $\mathrm{T}$ 1.1.7.17-18), sem ressaltar o problema de que o simples, como componente da extensão, nunca se torna concebível simplesmente pela decomposição das partes. Pelo contrário, afirma que Hume se vale do princípio de separabilidade "[...] em diversos pontos chaves no Tratado - por exemplo, ao argumentar contra a infinita divisibilidade do espaço, [... ]" (Garrett 2008, p.52). Esse deslize nos trilhos da argumentação encobre o fato de que o simples, nesse caso, envolve um minimum, que não pode ser alcançado pelo método da decomposição. Esse argumento é um ponto-chave para a construção do presente trabalho.

${ }^{10} \mathrm{O}$ artigo de Pappas traz uma fecunda segunda seção (1989, p.343-47) inteiramente dedicada às ideias de espaço e tempo na II Parte do Livro I do Tratado de Hume. No entanto, evita explorar a relação entre o princípio da cópia com um referente não extenso ou destituído de extensão, ou seja, o ponto. Pappas passa a discutir as nossas ideias de menor tamanho ou de mínima extensão (least-sized ideas - 1989, p.344), sem se perguntar se as propriedades desse mínimo podem atender ou não ao princípio da cópia, ou sem se referir ao modo pelo qual o princípio da cópia pode ser válido para ideias destituídas de extensão. A terceira seção insiste no hiato entre o qualitativo e o abstrato, apontando justamente sua periculosidade para a defesa do princípio da cópia em Hume, "pois o CT [copy thesis] é um primeiro passo vital e necessário na crítica destrutiva de Hume da metafísica tradicional" (Pappas 1989, p.348). Contudo, embora explore a tensão entre as ideias abstratas e o princípio da cópia, ressaltando que elas podem ser empregadas como um forte contra-argumento para se refutá-lo (1989, p.348-349), não retoma mais o problema do princípio da cópia aplicado ao elemento último da extensão.

${ }^{11} \mathrm{O}$ ponto envolve várias dificuldades para a análise dos princípios mais salientes do Tratado, a saber, da cópia, da separabilidade e da conceptibilidade (Garrett 2008, p.50-6). Todos esses princípios têm de admitir um uso particular para poder recebê-lo. Para salvar o princípio da cópia e a empiria do ponto, Hume então lança mão de um último recurso, que é dotá-lo de cor, o que ainda assim é um paradoxo para algo destituído de extensão.

${ }^{12}$ Baxter, por exemplo, percebe bem o problema: "Deve-se resistir à tentação de pensar que duas ideias mínimas são duas vezes mais extensas do que uma. Uma ideia mínima não tem comprimento algum [... ]" (2008, p.109). No entanto, ao examinar o problema, na sequência, o descreve a partir da composição do espaço, e não de sua decomposição. Há aqui uma incongruência entre o método de composição e decomposição, que vale ser ressaltada: é mais fácil compor a linha a partir dos pontos, que virão a ser seus elementos, do que decompor a linha para encontrar o seu imponderável elemento constituinte, que é destituído de extensão. A mancha de tinta, em Hume, é o recurso utilizado para enfrentar essa dificuldade.

${ }^{13}$ Sobre o princípio de distinção de razão, André Klaudat faz uma observação importante, mostrando também como sua aplicação depende de níveis metodológicos hierárquicos e inter-relacionados: "As distinções de razão vigem entre ideias 'simples' (Cf. T 67), pois no 
caso das complexas as ideias simples que as compõem são suscetíveis de serem separadas e distinguidas umas das outras segundo o princípio de que todas as ideias diferentes são separáveis" (1997, p.113). O autor aponta algo muito importante: a utilização da distinção de razão depende de um esgotamento do princípio da separabilidade. Ainda assim, podemos acrescentar, ela opera apenas em um nível residual, separando características simples de uma percepção indivisível do ponto de vista qualitativo. Mas não é um recurso, nota bene, para examinar o que contém uma percepção de um ponto de vista quantitativo.

${ }^{14} \mathrm{O}$ mesmo não pode ser dito para o célebre livro de Marina Frasca-Spada (1998a) sobre David Hume, que utiliza esse exemplo como um dos eixos de discussão do primeiro capítulo (1998a, p.11-55). Essa discussão recobre particular importância para a interpretação do princípio da cópia na II Parte do Livro I do Tratado, examinando os vários sentidos em que o termo ideia pode ser tomado como imagem (image), evitando-se o recurso de se o tomar por uma ideia relativa (relative idea). Discussão similar também é conduzida em dois artigos da autora (Frasca-Spada 1997, 1998b), que retomam o primeiro capítulo do seu livro.

${ }^{15}$ Como veremos mais adiante, Frasca-Spada (1998b, p.45), por exemplo, adota a segunda interpretação, como se a semântica das questões de fato pudesse impor um limite para as operações da matemática. Frasca-Spada destaca esse problema como central na discussão, inquirindo: "Não podemos nos mover de nível para nível sem fim? Por que Hume considera, como o ponto crucial de sua discussão, a incapacidade da mente de formar imagens na mesma proporção entre si quanto [a realizada entre] os números?" (1998b, p.33). Essa observação anuncia uma disjunção semântica muito importante, que será explorada no decorrer desse trabalho.

${ }^{16}$ Aqui surge um problema metodológico. Essa separação entre relações de ideias e questões de fato é da Investigação sobre o entendimento humano (IEH 4.1.1). Conquanto estejamos examinando as noções de espaço do Tratado (T 1.2), e ainda que a posição de Hume sobre a geometria no Tratado seja diferente (por exemplo, T 1.3.1.4) da sua posição na Investigação (por exemplo, IEH 4.1.1-2), defenderemos que essa distinção se torna importante aqui para explicitar o empirismo enquanto construção semântica em Hume.

${ }^{17}$ Pappas, por exemplo, cita essa passagem, sem comentá-la (1989, p.346). Baxter (2008, p.129-31) apresenta observações fecundas sobre a relação entre a imagem de uma impressão e as características geométricas que ela pode encerrar. No entanto, salienta que insistir na incongruência entre um ponto físico e sua forma matemática é desentender o centro da crítica de Hume, oferendo, assim, uma solução própria de leitura que encobre as dificuldades em questão, a saber: "A impressão recebida de um grão de areia quase não visível reflete com precisão um ponto matemático colorido ou tangível. Essa impressão não tem arestas, nem forma" (Baxter 1989, p.130). Ou seja, para Baxter, a impressão recebida de um grão de areia já esposa a forma de um ponto geométrico. Desse modo, impressão e forma geométrica se encaixam.

${ }^{18} \mathrm{O}$ ainda hoje notável artigo de George Pappas segue esse trajeto: “o grão de areia", "a mancha de tinta" e "o princípio de separabilidade" (1989, p.345-46). No entanto, e talvez movido por seu alvo principal, a saber, as ideias abstratas (T 1.1.7), Pappas não se detém para analisar nem a peculiaridade da mancha de tinta, uma vez que ela não é o único exemplo do simples em Hume, e nem ressalta que ela não é atingida pelo princípio de separabilidade. Aqui nós estamos insistindo no fato bem saliente de que a discussão do simples é bastante complexa em Hume, ou seja, há uma multivocidade no emprego do que seria uma impressão 
simples e sua ideia correspondente.

${ }^{19}$ Waxman indica essa dificuldade com uma pergunta bem perspicaz, a saber: "Por que, então, a descrição de Hume da origem da ideia de espaço/extensão centra-se em pontos ao invés de focar em regiões ou nos todos que eles compõem?" (2008, p.75). Ao comentar essa dificuldade, no entanto, não examina a passagem do ponto à extensão ou vice-versa, mas destaca a acribia com que percebemos as imagens no espaço.

${ }^{20}$ Como comentador arguto, Kemp Smith registra o problema, e utiliza um termo técnico, "corolário" (corollary), para indicar isso. Ou seja, mostra que, em sentido rigoroso, isso pode ser extraído das próprias afirmações de Hume, como algo que reside em seus pressupostos. Contudo, na sequência, não prossegue na exegese desse corolário, mas volta a discutir os limites da nossa percepção (1941, p.278).

${ }^{21} \mathrm{~A}$ noção de um tempo composto de partes não-coexistentes, que ainda assim não pode ser concebido a partir de suas partes tomadas isoladamente, aparece claramente na Seção III desse texto (em particular, em $\mathrm{T}$ 1.2.3.8). O vocabulário impactante de Waxman é retirado dessa passagem.

${ }^{22}$ Nas "Anotações dos editores", os Nortons fazem um bom apanhado desse debate (D. Norton \& M. Norton 2007, p.709-711), confrontando os partidários do atomismo e defensores da divisibilidade infinita. A dificuldade está na raiz do debate, porque os primeiros têm uma concepção física do debate e os últimos uma concepção matemática. No seio desse debate aparecem Bayle, Hobbes, Charleton, Chambers e outros. Isso mostra que Hume estava frequentando uma discussão bem estruturada e que já abrigava posições bem talhadas.

${ }^{23}$ Newman principia seu artigo pondo como baliza da discussão o fato de que "a capacidade da mente é limitada [...]" (1981, p.02). Cachel afirma que "[... o pressuposto inicial tomado pela filosofia humeana é a finitude da mente humana [... $]$ (2017, p.19). Kemp Smith também acentua o problema do que denomina os minima sensibilia (1941, p.276-79), conquanto procure mostrar que a questão da não extensão tem implicações diretas para o princípio da cópia. Flage, para ultrapassar o limite da percepção desse mínimo sensível, traça uma distinção entre ideias positivas e relativas, defendendo a interpretação de que "[...] é razoável compreender sua discussão [de Hume] da milésima parte de um grão de areia como resultado da operação de uma ideia relativa sobre a imagem mental de um grão de areia" (1981, p.69). Isso mostra o quão diferente podem ser as inflexões de leitura desse texto de Hume. Entendemos que a questão de Hume, na II Parte do Tratado, diz respeito não somente ao que pode ser percebido na extensão, mas também ao modo pelo qual pode ser pensada a geometria, se ela for construída a partir de dados perceptuais. A interpretação aqui proposta procura fazer essas duas questões andarem juntas na exegese dessa passagem do Tratado.

${ }^{24}$ Bayle insiste no paradoxo da divisibilidade infinita de tudo o que é extenso: "Não é menos impossível ou inconcebível que seja composto dos átomos de Epicuro, quer dizer, de corpúsculos extensos e indivisíveis; pois todo extenso, por mais pequeno que ele possa ser, tem um lado direito e um lado esquerdo, um lado de cima e um lado de baixo [... ]" (1740, nota G, p.540). Bayle percebe e explicita bem o paradoxo que surge quando se procura destituir o extenso de partes.

${ }^{25}$ A dificuldade, no que tange aos atomistas, não está na distinção semântica entre o que pode ser finita e infinitamente divisível, mas repousa silente na pressuposição de que há um ponto físico indivisível, ou seja, destituído de partes. Cummins também destaca bem esse flanco da discussão: "O problema com os pontos físicos (também chamados de átomos 
epicuristas) é que eles são impossíveis. Ou assim é alegado. Um ponto físico é definido como uma entidade que é ao mesmo tempo extensa e indivisível. No entanto, o que é extenso é composto e o que é composto é composto de partes distintas. Além disso, partes distintas umas das outras são separáveis umas das outras, e qualquer coisa que tem partes separáveis umas das outras é divisível" (1990, p.300).

${ }^{26}$ Definição 1 do Livro I de Euclides (2009, p.97).

${ }^{27}$ Essa leitura pode explicitar o caráter heurístico ainda presente nos apontamentos de ambos os autores, evitando uma interpretação tão depreciativa como a feita por Kemp Smith em relação a Bayle (1941, p.285) e a Hume (1941, p.287).

${ }^{28}$ Bayle comenta o seguinte: "Que resta, portanto, a dizer, a não ser que esta extensão não pode existir, e que desse modo todas as propriedades dos círculos e dos quadrados, etc., são fundadas sobre linhas sem largura que não podem existir senão idealmente? Notai que nossa Razão e nossos olhos são igualmente enganados nesta matéria” (1740, nota G, p.541). Essa concepção da existência ideal dos objetos matemáticos organiza toda a leitura de Bayle em face do seu ceticismo perceptivo. E dela emergem duas esferas incongruentes, a dos objetos empíricos e a das estruturas matemáticas.

${ }^{29}$ No parágrafo 13 dos Prolegômenos (1983), Kant procura justificar que as formas puras da intuição asseguram a aplicação da matemática aos objetos empíricos, na medida em que elas são as condições tanto das construções do geômetra quanto da exibição dos fenômenos. Como para Bayle as construções geométricas se dão em um domínio inteligível, elas desempenham o papel de uma ficção em relação a qualquer dado empírico ou em relação ao espaço que lhe está aderido. Temos em Bayle, portanto, uma concepção invertida em relação àquela defendida por Kant.

\section{Agradecimentos}

Esse artigo apresenta resultados de um projeto financiado pelo Conselho Nacional de Desenvolvimento Científico e Tecnológico - CNPq, ao qual o autor está vinculado por bolsa produtividade e a quem manifesta seu agradecimento. Também fica registrada a dívida do autor com a leitura atenta dos pareceristas da revista Principia: an International Journal of Epistemology. Suas observações penetrantes e exigências precisas conduziram não só a um desdobramento de vários argumentos desse trabalho, mas também à explicitação e à ampliação do aparato dessa leitura, tornando o texto mais claro em seus propósitos e mais acessível ao leitor. 